\title{
Research on Demand Response Management System in Smart Network
}

\author{
Junyan LI \\ Chinacomm Design \& Consulting Co., Ltd., Beijing, China
}

\begin{abstract}
Demand response is one of the key research in Smart Network, it is the general trend of the social and economic development. Demand response in Smart Network is analyzed which describes new functional response requirements, and put forward the technology response system in Smart Network. The key technology of the wholesale electricity market, large scale clean energy consumption and home energy management system is detailed studied. The current implementation of demand response problems is pointed out that provides reference for the development of the demand response.
\end{abstract}

KEYWORD: Demand response; Smart Network; Demand management; Detection; Communication

\section{INTRODUCTION}

Demand response can effectively alleviate the transmission and generation capacity expansion problem, which is an important part of Smart Network. Smart Network set up efficient electricity information service system and service platform and build new power supply and demand relationship including user power flow, information flow, business flow and real-time interaction. Interactive strategy stimulate user participation in demand response and directly remote optimization control, realize flexible power load, guide the user or directly optimize power consumption economic operation support power supply side. Power system construction directly determine the quality of power energy use efficiency, economic operation and orderly use of electricity intelligent influencing power grid construction, energy saving and environmental protection, power quality management.

Recent blackouts have indicated the inefficiency and serious reliability issues of the traditional grid. Therefore, it is essential to transform the traditional power grid into a more responsive, efficient and reliable system. Smart Network is a future power grid system that incorporates a smart metering infrastructure capable of sensing and measuring power consumption from consumers with the integration of advanced information. The role of demand resources in the competitive market is adopted with the development of Smart Network and power market. The electric power market demand response design the resources of supply side and demand side that increases the demand side in the function in the market through the price signals and incentive mechanism. Flexible interactive intelligence is the development trend of electricity demand response.

Flexibility is the important feature of electrical intelligent. The randomness and volatility is the main problem of large scale wind power. Inhibition of wind power fluctuation, smooth access to the grid is of great practical significance. The demand of electricity consumes has been growing due to increased use of machines and the new types. Thus the power generation, distribution and consumption is efficient, more economical and more reliable in the Smart Network network.

\section{THE MECHANISM OF DEMAND RESPONSE}

\subsection{The realization of demand response}

Demand response is that the power users to change the power mode, and respond mechanism according to the price signals. The implementation of demand response program is the key of the response behavior of power user incentives for electric power company, and due to changing in the load characteristics of electric users in the electric mode. Demand response measures can be divided into two types according to different user mode response: the price of demand response and incentive based demand response.

The user are arranged generally through the optimization decision making smart interactive 
terminal and energy management system for production when the received power company demand response project requirements. The user cost is generally divided into the purchase cost, service cost and outage cost. User interrupt cost function can be expressed as one type, two type, three type and index. Industrial users are closely related to the production of electric equipment used in process. Commercial users of electricity consumption are the main commercial building electrical according to various incentive policies and operation information of commercial user side of each system energy use and the grid side of energy, provide the best management plan for the user. Home energy management system of residential users through intelligent home furnishing according to use time pricing and the excitation signal of household appliances optimization.

\subsection{Demand response benefit evaluation}

Demand response benefit of the project includes the user side electricity saving, economic compensation, the grid side power purchase cost reduction, the cost reduction etc. Quantitative analysis of demand response is an important significance for the development of the implementation efficiency for the development potential, demand response to promote demand response program.

The design of incentive mechanism is the key demand response. Based on the incentive demand response programs, user participation in demand response can be obtained by two compensation amount. The first method is evaluated on the basis of market power cut price. The second method is based on the user declaring the interruptible load capacity subsidies. For the second cases, the user can provide price through incentive incentive mechanism. The two methods can reflect the outage cost.

\section{THE APPLICATION OF LARGE-SCALE CLEAN ENERGY CONSUMPTION OF DEMAND RESPONSE}

Competitive market power in a longer period of time is not ideal due to the characteristic of electric power commodity. Demand side and supply side equally can form the real electricity market operation. Demand response is to ensure the stability of unilateral market, oligopoly market force to reduce power plant. According to the model in micro economics, raise the price elasticity of demand is an effective method the market force.

Randomness and fluctuation of wind power is the great disadvantage, demand side response in wind power operation is the good solution for multiple countries, requiring the use of demand side response to protect the wind power integration. Real time pricing mechanism is guiding the user in the evening more electricity, reducing the burden of system operation, improving the wind power receptiveness.

In Smart Network, the power fluctuation of load can be employed resident of direct load control and conventional power generation, energy storage to suppress the distributed new energy caused by. In order to use more demand in response to alleviate the fluctuation of new energy power generation, we are using the cross spectrum analysis method in frequency domain, the frequency of wind power fluctuation curve and the user demand curve for comparison for matching wind power demand response target user group strategy in the analysis of wind response on demand. A greener environment along with the desire for better utilization of renewable energy resources is one of many important objectives of deploying the Smart Network. Industrial scale wind and solar power plants are being connected to the grid as part of a worldwide effort to reduce carbon emissions. However, the deployment of renewable energy resources presents a major challenge in system operations due to the inherently unpredictable nature of renewable energy generation, forecasting uncertainty and limited control capabilities. As a result, a high performance, reliable and secure communication and control network is the key point of successful renewable energy integration and deployment. For example, variation in the output power of renewable sources caused by changes in weather and time of day are driving the control of distribution network to finer and finer time scales.

\section{THE KEY TECHNOLOGIES OF HOME ENERGY MANAGEMENT SYSTEM}

The technical system of Smart Network environment home energy management system includes load, energy storage systems and renewable energy. The physical layer consists of a load, energy storage systems and renewable energy types of equipment structure. Home energy management system can realize energy saving and emission reduction, demand response, renewable energy access, electric vehicle access system function.

In the system, the detection is the basis for optimal scheduling and monitoring, optimal the core, the network communication technology is the key technology to realize the system. In addition, wind power, photovoltaic power generation output prediction, forecasting electricity load forecasting can directly use the existing prediction algorithm. 

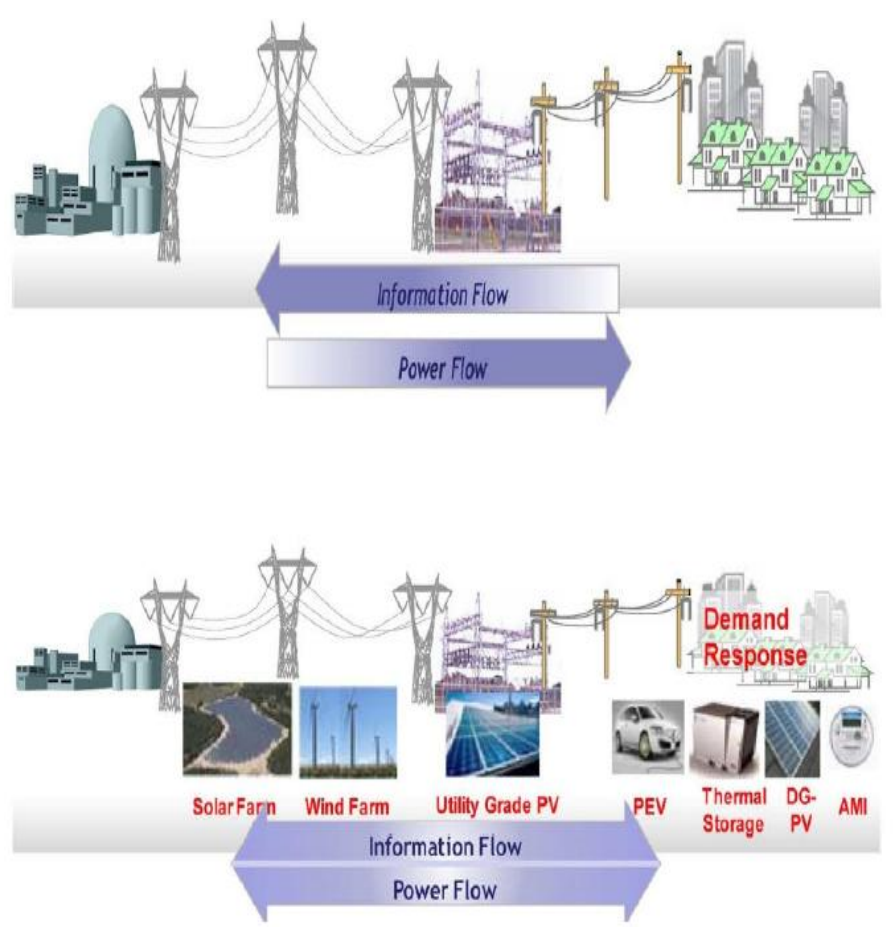

Figure 1. Power information in traditional plants and smart network

\subsection{Detection technology of home energy management system}

Compared with the traditional home energy management, the total consumption in home energy management system detect home users. Traditional detection methods need to install sensors for each object detection, installation. Insufficient load detection method can make up the traditional method. Non-intrusive load method only needs to install a small amount of sensor to detect the key nodes in the family environment in electricity use, and then through the algorithm to determine the working status and power consumption.

Non-intrusive load detection method uses the instrument less, low cost, easy installation and maintenance which is easy to be accepted by users, but for the energy consumption is small, the working mode of complex equipment identification more difficult, the recognition accuracy decline. Most algorithms require a lot of training and calibration process.

Detection and recognition of the user in the family environment and behavior of physical, using certain method model of user behavior prediction is optimized dispatching operation of equipment for home energy management system. Detection means in addition to infrared method. At present, the detection and identification of personnel activities within the home environment is mainly concentrated in the single user, there are often multiple users in real home environment, the behavior of coupling between them has increased, behavior recognition and prediction, but the recognition and prediction results have important value for improving of optimal scheduling of home energy management system. Therefore, non-invasive detection and recognition algorithm are the future research of the key technologies in the field of home system testing.

\subsection{Network communication technology of home energy management system}

Home energy management system in Smart Network environment can be optimized with the management, and a lot of families will work together. Therefore, home energy management system in Smart Network environment need the home area network, local area network and wide area network (wide area network) three kinds of network support. Each home energy management system is a home area network and external network for information exchange interface. Many smart meters in the same region of small network, from all the smart meter data aggregation in the area of Internet data center, and then through the wide area network to the power companies used to achieve using energy metering, load prediction function; electric power company issued.

Due to user movement, increasing or decreasing the electricity load operation will cause frequent network topology changes which is set up by wire home energy management system for communication network. Wireless communication technology is the mainstream technology of the current set up home energy management system home area network, in ZigBee technology due to the low-power, self organization, has the advantages of flexible low cost, it is a communication way of home energy management system which is the most commonly used home area network.

Table 1. Home local area network communication network technology

\begin{tabular}{|c|c|c|c|}
\hline mode & Technical standard & maximum rate & range \\
\hline \multirow{4}{*}{ Wired } & HomePlu & 14-200Mbps & $300 \mathrm{~m}$ \\
\hline & Ethernet & 10-1000Mbps & $100 \mathrm{~m}$ \\
\hline & $\mathrm{X} 10$ & $50-60 \mathrm{kbps}$ & $300 \mathrm{~m}$ \\
\hline & Insteon & $1.2 \mathrm{kbps}$ & $3000 \mathrm{~m}$ \\
\hline \multirow{7}{*}{ Wireless } & Z-Wave & 40kbps & $30 \mathrm{~m}$ \\
\hline & $\mathrm{WiFi}$ & 11-300Mbps & $100 \mathrm{~m}$ \\
\hline & \multirow{2}{*}{ 6LowPAN } & $250 \mathrm{kbps}$ & \\
\hline & & $40 \mathrm{kbps}$ & $10-75 \mathrm{~m}$ \\
\hline & \multirow{3}{*}{$\mathrm{ZiBe}$} & $20 \mathrm{kbps}$ & \\
\hline & & $250 \mathrm{kbps}$ & $10-75 \mathrm{~m}$ \\
\hline & & $40 \mathrm{kbps}$ & \\
\hline
\end{tabular}

Family environment contains various types equipment which is produced by different manufacturers, using different communication standards. ZigBee technology in the field has been widely used, but has formed a unified communication standard for home energy management system home area network. It increases the difficulty of system integration. 
Hot interoperability research on energy management system is still family. Through intelligent appliance manufacturers jointly are developing in home energy management system standard, intelligent home appliances of the future detection and communication network capability. Intelligent home is set up according to the same standard networking, self reporting its energy situation. The formulation of the standards is conducive to the solution of existing home energy management system energy low detection accuracy, equipment interoperability difficult problem, reduce implementation costs of home energy management system, improving the user acceptance.

The problem of network security is a Smart Network environment system network communication energy management another research hotspot. In the Smart Network, the user can monitor the home environment of the equipment through the internet and the mobile network. At the same time, home energy management system for collecting a large number of user electric energy data. The illegal user can through the user electric energy data analysis to infer the user habits, resulting in loss of user privacy. Illegal intrusion will pose a threat to the safe operation of the system. In addition, home energy management system for collecting a lot of user electric energy data, including user privacy. One of the directions of how to meet the normal demand in the premise of company as possible under the protection of user privacy is also studying.

\section{CONCLUSION}

In this paper, we have proposed a Research on Demand Response Management System for Smart Network. We have designed a distributed method. Application of demand response makes power load uncontrollable part of the flexible and controllable, the power load with certain adaptive ability which is a major change in power system. Demand response can be used for the power system peak load peak, and the equipment has the ability to automatically track changes in the system which is to protect the power grid safety. The demand side management of urban comprehensive pilot will be on demand response that is greatly promoted through the price mechanism and market means.

\section{REFERENCES}

[1] HAZAS M, FRIDAY A, SCOTT J, Look back before leaping forward: four decades of domestic energy inquiry. IEEE Pervasive Computing: 201, 10(1):13-19.

[2] OZTURK SENTHILKUMAR D, KUMAR S. An intelligent home energy management system to improve demand response. IEEE Trans on Smart Network, 2013, 4(2): 694-701.

[3] SUNDRAMOORTHY V'COOPER Q LINGE N. Domesticating energy-monitoring systems: challenges and design concerns. IEEE Pervasive Computing, 2011, 10(1): 20-27.

[4] CHEN C. A communication-based appliance scheduling scheme for consumer-premise energy management systems. IEEE Trans on Smart Network, 2013, 4(1): 56-65. 